\title{
AÇÃO ANTIOXIDANTE DOS ALIMENTOS
}

\author{
Antioxidating Food Action
}

Acción Alimentaria Antioxidante

Dafne Nayara Quinta Barbosa, Haylla Freiria Maganhoto de Sousa, Rodolfo Castilho Clemente

Laboratório de Ciências Básicas e da Saúde, Curso de Nutrição, Universidade Federal do Tocantins, Palmas, Brasil.

*Correspondência: castilho@mail.uft.edu.br.

Nas últimas décadas, com a transição epidemiológica e elevação da renda média da população, novos padrões de consumo e estilo de vida foram adotados. Neste contexto, observou-se a necessidade de investir em pesquisas que visam descobrir maneiras sustentáveis de prevenir doenças crônicas nãotransmissíveis, visto que houve um crescente número de diagnósticos. A partir de então, os alimentos passaram a ser vistos, além de seguros e atrativos, importantes na prevenção de doenças crônicas e manutenção do bem-estar físico e mental (NERINUMA et al., 2017).

Os alimentos funcionais, além de conterem os nutrientes essenciais, possuem outros componentes não nutritivos que desempenham efeitos fisiológicos importantes, promovendo saúde aos indivíduos que os consome. Os efeitos positivos, em sua maioria, se devem à presença de substâncias bioativas com propriedades específicas, como: antioxidantes, antiinflamatórias e imunomodulatórias (PISOSCHI, 2015). Desta maneira, houve um constante aumento de interesse pelos problemas relacionados ao estresse oxidativo e radicais livres, que podem causar o agravamento e surgimento de diversas patologias que causam injúria celular.

Os radicais livres são espécies reativas de oxigênio e/ou nitrogênio que podem desempenhar funções benéficas ou deletérias no organismo. Porém o excesso dos mesmos pode levar a diversas situações, como mutações, ruptura da membrana celular e morte celular, frequentemente associado ao surgimento de doenças crônicas não transmissíveis e ao envelhecimento celular (CERQUEIRA, MEDEIROS, AUGUSTO, 2007).

Entende-se, então, a importância do estudo dos alimentos com capacidade de anular os radicais livres e controlar o estresse oxidativo. As moléculas antioxidantes possuem a capacidade de capturar os radicais livres e evitar a propagação dos efeitos deletérios. Os principais compostos descritos na literatura são as vitaminas C, E e A, os carotenoides e flavonoides.

A vitamina C é hidrossolúvel e envolvida em múltiplas funções biológicas, como na absorção do ferro dietético. Além da função antiescorbútica, é um potente agente redutor capaz de eliminar espécies altamente reativas de oxigênio. $\mathrm{O}$ mesmo é naturalmente encontrado, em particular, em frutas cítricas.

Tocois e tocotrienois são substâncias presentes em alimentos como vegetais verdes, gema de ovo, manteiga e carnes. A função deles é prevenir a peroxidação da bicamada lipídica celular e das lipoproteínas de baixa densidade (LDL), principais 
responsáveis pelo transporte de colesterol do fígado para os tecidos periféricos. Por isso, são essenciais no retardo do desenvolvimento de aterosclerose e sua deficiência está relacionada à neurodegeneração (ATKINSON, EPAND, EPAND, 2008).

Já os carotenoides são pigmentos naturais sintetizados por plantas, algas, bactérias, fungos e leveduras, responsáveis pelas tonalidades que podem variar entre amarelo e vermelho. Entre eles, os principais são: $\beta$-caroteno e o licopeno. São compostos lipofílicos sendo encontrados principalmente em tecido adiposo e atualmente, seu consumo se associa a menor risco de câncer e doenças cardiovasculares (SAINI, KEUM, 2018).

Flavonoides, ou também chamados de Polifenóis, são os antioxidantes mais abundantes da dieta, onde o consumo diário pode atingir até 1 grama. Dentre eles, as maiores classes são flavonóis e catequinas. Estes formam complexos com açúcar, lipídios, aminas e ácido carboxílicos, e estudos in vitro indicam que polifenóis podem de fato ter ações anticarcinogênicas e antiaterogênicas. (KHALID ET AL., 2019). Já as catequinas, que estão presentes em grandes quantidades no chá verde e no cacau, estão entre os flavonoides polifenólicos mais potentes como antioxidantes.

Não há evidências comprovadas de que o consumo de alimentos ricos em antioxidantes ao longo da vida acarrete prejuízos à saúde. De forma contrária, há evidências claras de que estejam diretamente associados à um envelhecimento saudável e aumento da qualidade de vida. Contudo, há estudos que comprovam maior eficácia advinda de fontes alimentares em comparação aos suplementos (PEREZ-VIZCAINO, FRAGA, 2018).

Assim, uma dieta baseada em consumo variado e regular de alimentos frescos, in natura e com grande presença de frutas e hortaliças mostra-se indispensável no combate e prevenção à diversas doenças, especialmente às doenças crônicas nãotransmissíveis. Compreende-se a importância substancial de medidas dietoterápicas, como a ingesta adequada de nutrientes com ação oxidante para o equilíbrio fisiológico e uma vida mais saudável. (NERI-NUMA et al., 2017).

\section{REFERÊNCIAS}

ATKINSON, J.; EPAND, R. F.; EPAND, R. M. Tocopherols and tocotrienols in membranes: A critical review. Free Radical Biology and Medicine, v. 44, n. 5, p. 739-764, 2008.

CERQUEIRA, F. M.; MEDEIROS, M. H. G.; AUGUSTO, O. Antioxidantes dietéticos: Controvérsias e perspectivas. Quimica Nova, v. 30, n. 2, p. 441-449, 2007.

KHALID, M.; RAHMAN, S.; BILAL, M.; HUANG, D. Role of flavonoids in plant interactions with the environment and against human pathogens - A review. Journal of Integrative Agriculture, v. 18, n. 1, p. 211-230, 2019.

NERI-NUMA, I. A.; SANCHO, R. A. S.; PEREIRA, A. P. A.; PASTORE, G. M. Small Brazilian wild fruits: Nutrients, bioactive compounds, healthpromotion properties and commercial interest. Food Research International, v. 103, n. October 2017, p. 345-360, 2018.

PEREZ-VIZCAINO, F.; FRAGA, C. G. Research trends in flavonoids and health. Archives of Biochemistry and Biophysics, v. 646, n. March, p. 107-112, 2018.

PISOSCHI, A. M.; POP, A. The role of antioxidants in the chemistry of oxidative stress: A

review. European Journal of Medicinal Chemistry, v. 97, p. 55-74, 2015.

SAINI, R. K.; KEUM, Y. S. Carotenoid extraction methods: A review of recente developments. Food Chemistry, v. 240, n. July 2017, p. 90-103, 2018. 